\title{
Color vision in the giant panda (Ailuropoda melanoleuca)
}

\author{
ANGELA S. KELLING \\ Zoo Atlanta, Atlanta, Georgia \\ and Georgia Institute of Technology, Atlanta, Georgia \\ REBECCA J. SNYDER \\ Zoo Atlanta, Atlanta, Georgia \\ M. JACKSON MARR and MOLLIE A. BLOOMSMITH \\ Georgia Institute of Technology, Atlanta, Georgia \\ WENDY GARDNER \\ Zoo Atlanta, Atlanta, Georgia \\ and \\ TERRY L. MAPLE \\ Georgia Institute of Technology, Atlanta, Georgia
}

\begin{abstract}
Hue discrimination abilities of giant pandas were tested, controlling for brightness. Subjects were 2 adult giant pandas ( 1 male and 1 female). A simultaneous discrimination procedure without correction was used. In five tasks, white, black, and five saturations each of green, blue, and red served as positive stimuli that were paired with one or two comparison stimuli consisting of 16 saturations of gray. To demonstrate discrimination, the subjects were required to choose the positive stimulus in 16 of 20 trials ( $80 \%$ correct) for three consecutive sessions. Both subjects reached criterion for green and red. The female subject also reached criterion for blue. The male was not tested for blue. This study is a systematic replication of Bacon and Burghardt's (1976) color discrimination experiment on black bears. The results suggest that color vision in the giant panda is comparable to that of black bears and other carnivores that are not strictly nocturnal.
\end{abstract}

Color vision is defined as the ability to discriminate multiple wavelengths of the visible spectrum independently of their respective brightness or saturation. Animals need receptors with at least two different spectral sensitivities to be able to perceive color (see, e.g., Jacobs, 1993). But the presence of two photopigments in the retina does not prove that an animal has color vision. Instead, color vision and its dimensionality must be ascertained through behavioral study (Jacobs, 1993). Various training methods for studying color vision in animals have been developed (Jacobs, 1981; Tansley, 1965). Such methods necessarily involve control procedures because color discrimination can be based on cues other than hue, such as brightness. Early color vision experiments have often been questioned, because they did not control for brightness (Jacobs, 1981). Potential fluctuations in thresholds

This research was conducted at Zoo Atlanta. The authors thank Patty Goff and Jennifer Milholen for their assistance with data collection, and Nicholas Kelling for building the apparatus. Correspondence concerning this article should be addressed to A. S. Kelling, School of Psychology, Georgia Institute of Technology, 654 Cherry Street, Atlanta, GA 303320170 (e-mail: akelling@zooatlanta.org). that Jacobs (1981) claims are inevitable in psychophysical measurements make a precise determination of brightness equality impossible. The most frequent strategy to control for brightness is to make it an irrelevant cue by presenting the color with enough saturations (hereafter referred to as shades) of gray to prevent discrimination by brightness alone (see, e.g., Chausseil, 1992).

Most diurnal animals are presumed to have some degree of color vision (Jacobs, 1981). Within the order Carnivora, only three species have been well studied: dogs (Canis familiaris), cats (Felius catus), and raccoons (Procyon lotor). Dogs have been shown to be dichromats (see, e.g., Jacobs, Deegan, Crognale, \& Fenwick, 1993; Neitz, Geist, \& Jacobs, 1989). It was long believed that cats were colorblind (e.g., DeVoss \& Ganson, 1915; Walls, 1942), but more recent studies have found that cats have at least dichromatic color vision (e.g., Daw \& Pearlman, 1970; Ringo, Wolbarsht, Wagner, Crocker, \& Amthor, 1977). It has been proposed that the early negative findings may have resulted from stimulus size, shape, and viewing distance (Loop, Bruce, \& Petuchowski, 1979) or illumination (Tritsch, 1993). The two nocturnal procyonids that have been studied, raccoons and kinkajous (Potos flavus), were found to lack cone-based color vision (e.g., Chausseil, 
1992; Jacobs \& Deegan, 1992; Gregg, Jamison, Wilkie, \& Radinsky, 1929; Zeveloff, 2002), whereas the diurnal procyonid, the coati (Nasua nasua), was able to discriminate colors (Chausseil, 1992).

One family of carnivores in which vision has not been well studied is the ursids. Bears have often been thought to have poor vision (for discussion, see Bacon, 1973, and Shepard \& Sanders, 1985), perhaps because of their welldeveloped olfactory and auditory systems. However, there have been many claims, though there has been little empirical evidence, that various bear species possess color vision (McNamee, 1984; Shepard \& Sanders, 1985), with some authors postulating that color vision would facilitate the recognition of edible plant matter (Pelton, 2000; Van Valkenburgh, 2000). The primary experimental evidence for bear color vision comes from Bacon and Burghardt (1976). They found that black bears could discriminate visual stimuli on the basis of wavelength, with one subject learning to discriminate blue and the other to discriminate green from grays.

Very little is known about the sensory capabilities of another ursid, the giant panda (Ailuropoda melanoleuca), beyond that of chemical communication (Swaisgood, Lindburg, \& Zhang, 2002; Swaisgood, Lindburg \& Zhou, 1999). Other sensory systems have not yet been investigated, and almost nothing is known about the visual capabilities of this species. Giant pandas use some visual signals as a means of communication. They communicate with body postures (Schaller, Hu, Pan, \& Zhu, 1985) and visual markings such as bark stripping and clawing (Laidler \& Laidler, 1992; Schaller et al., 1985). Therefore, giant pandas must have acute enough vision to distinguish signals made by conspecifics, but such signal detection would not require color vision.

$\mathrm{Hu}$ (2001) found that the eye of the giant panda contains rods and cones, with rods outnumbering cones, suggesting that giant pandas possess acute night vision while still being capable of daylight and color vision. Giant pandas are not nocturnal; they tend to be polycyclic, with activity peaks in the early morning and late afternoon (Schaller et al., 1985). With these activity trends, giant pandas could be expected to possess well-developed vision, including the ability to discriminate colors.

This study is a systematic replication of Bacon and Burghardt's (1976) color discrimination experiment in black bears, with the inclusion of brightness discrimination, as well as modifications to accommodate testing giant pandas. The purpose of the present study was to assess the limits of giant panda color discrimination. The study was divided into two phases: brightness and hue discriminations. Both phases required the subjects to select a positive stimulus from shades of gray. Brightness discrimination was conducted to determine whether giant pandas could be trained to respond to the testing apparatus and learn a visual discrimination task using a simultaneous discrimination procedure. The second phase of this study, hue discrimination, was conducted to determine whether giant pandas could distinguish green, red, and blue from various shades of gray.

\section{METHOD}

\section{Subjects}

Subjects were 1 male and 1 female adult giant panda on loan to Zoo Atlanta from the Chengdu Research Base of Giant Panda Breeding. The male (Studbook No. 461) was born September 9, 1997. The female (Studbook No. 452) was born August 25, 1997 (Xie \& Gipps, 2003). The subjects were housed indoors from 1700 to $0900 \mathrm{~h}$ in two to three off-exhibit enclosures measuring $9.5 \mathrm{~m}^{2}$. From 0900 to $1700 \mathrm{~h}$, the subjects were housed on exhibit in either an indoor glass-fronted room $\left(63 \mathrm{~m}^{2}\right)$ or an outdoor enclosure $\left(232 \mathrm{~m}^{2}\right.$ or $\left.325 \mathrm{~m}^{2}\right)$. During this study, the subjects were tested in an off-exhibit steel mesh enclosure measuring approximately $6.25 \mathrm{~m}^{2}$. This area provided constant lighting for all sessions. The subjects were tested between 0730 and $0830 \mathrm{~h}$.

\section{Stimuli}

The stimuli consisted of green, red, blue, and gray (ranging from white to black) color rectangles $(17.15 \times 22.86 \mathrm{~cm})$ created with Microsoft Paint Version 5.0 and printed on a color laser printer. Each rectangle was laminated to prevent deterioration. Five shades each of green, red, and blue and 18 shades of gray, including white and black, were created. White was the positive stimulus during training and for Task 1. Black was the positive stimulus in Task 2. In Tasks 3,4 , and 5, five shades each of green, blue, and red, respectively, served as positive stimuli. All positive stimuli were paired with one or two comparison stimuli, selected from 16 shades of gray.

To ensure that some shades of gray were brighter and some were dimmer than all the shades of green, red, and blue, the transmission spectrum of each shade of green, red, blue, and gray was plotted using a spectrometer (Spectrascan 650, manufactured by PhotoResearch; see Figures 1 and 2). The different shades of green, red, and blue as positive stimuli required the subjects to discriminate several shades of each color. Thus, a subject was unable to perform these discriminations on the basis of brightness alone, because depending on the trial, the positive stimulus could be the brightest, the dimmest, or an intermediate level of brightness. Furthermore, because an assortment of shades was used, the brightness relationship was not consistent (see, e.g., Bacon \& Burghardt, 1976; Birgersson, Alm, \& Forkman, 2001; Chausseil, 1992; Muntz \& Cronley-Dillon, 1966).

\section{Apparatus}

The upper piece of the test apparatus (see Figure 3 ) was a wooden board $(91.44 \times 8.89 \times 1.91 \mathrm{~cm})$ supporting a removable PVC rod $(91.44 \times 2.54 \mathrm{~cm}$ in diameter). Three plastic clips attached to the PVC rod, evenly spaced at $31 \mathrm{~cm}$ apart, held the stimuli.

The lower piece of the apparatus was a board $(72.39 \times 6.03 \times$ $1.91 \mathrm{~cm})$ with drilled holes that allowed the insertion of PVC pipe extensions $(31.75 \times 2.54 \mathrm{~cm}$ in diameter $)$. The PVC pipes were capped on the ends that extended into the subject's area in order to shield the ends' sharp edges. A metal bolt longer than the diameter of the pipe was secured through each pipe on the experimenter's side to prevent the subject from being able to pull the pipe completely through the mesh. Each piece of the apparatus was attached to the experimenter's side of the mesh enclosure, requiring the subjects to look through spaces in the mesh (measuring approximately $5 \times$ $5 \mathrm{~cm}$ ) to see the stimuli, which were flush against the mesh. Only the PVC pipes extended through into the subject's enclosure. The PVC pipes served as the response bars.

The apparatus was placed at heights that simultaneously allowed the subjects visual access to the stimuli and visual and paw access to the response bars. The upper piece was placed approximately $1 \mathrm{~m}$ above the floor, and the lower piece was placed about $0.5 \mathrm{~m}$ above 


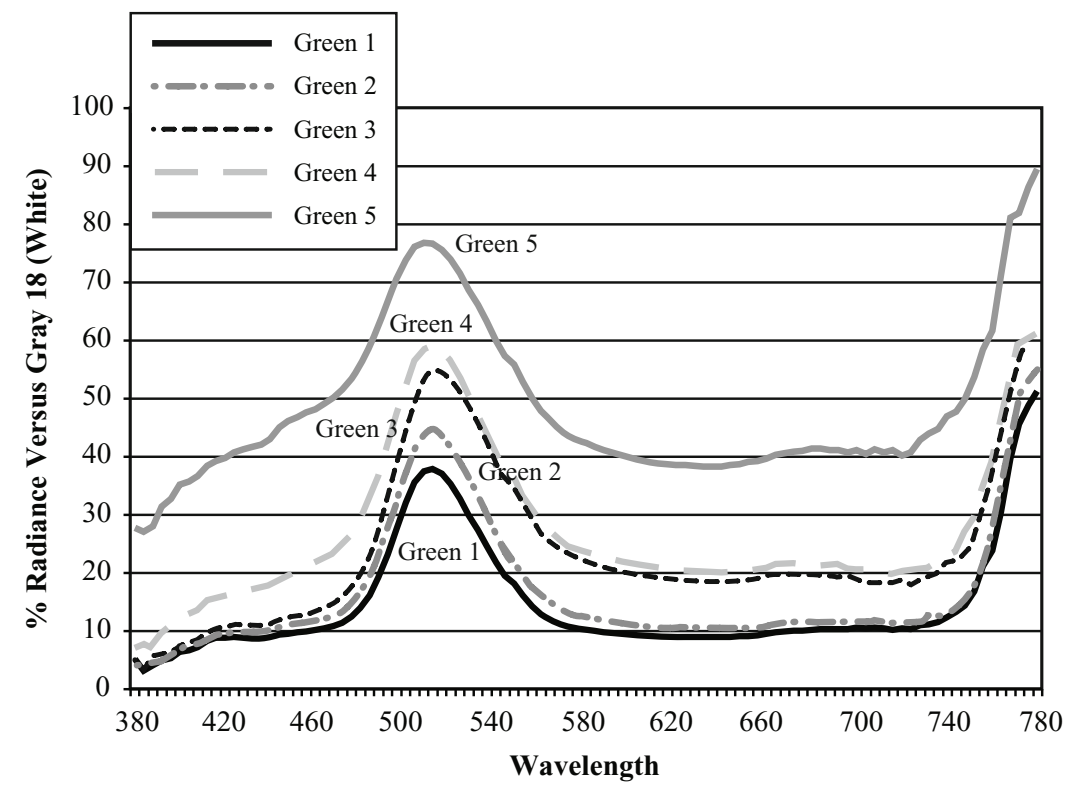

Figure 1. Transmission spectra for the five shades of green (Green 1 is the darkest and Green 5 is the lightest shade) in comparison with the white stimulus used in the study.

the floor. The optimal placement of the apparatus was determined for each giant panda according to its height, and thus the apparatus was placed slightly higher for the male than for the female.

\section{Training Procedure}

Before the experiment began, the subjects were habituated to the apparatus and reinforcement procedure. Three giant panda keepers who routinely cared for the subjects used standard behavioral shaping procedures to train the subjects to respond to the apparatus. Each subject had previously been trained to raise its forepaw and place the pad of its paw flat against the mesh front of its enclosure when given the command "paw." This command was shaped into the behavior "push," in which the subject raised its forepaw and placed it against the capped end of any one of the PVC pipes extending into the testing area. This behavior pushed the pipe through the board, so that the pipe then extended outside of the testing enclosure onto the experimenter's side. Thus, the experimenter judged the subject's response to the stimuli by the movement of these pipes. Initially, the subject was allowed to push any pipe. Gradually, the behavior was differentially reinforced so that the subject received food reinforce-

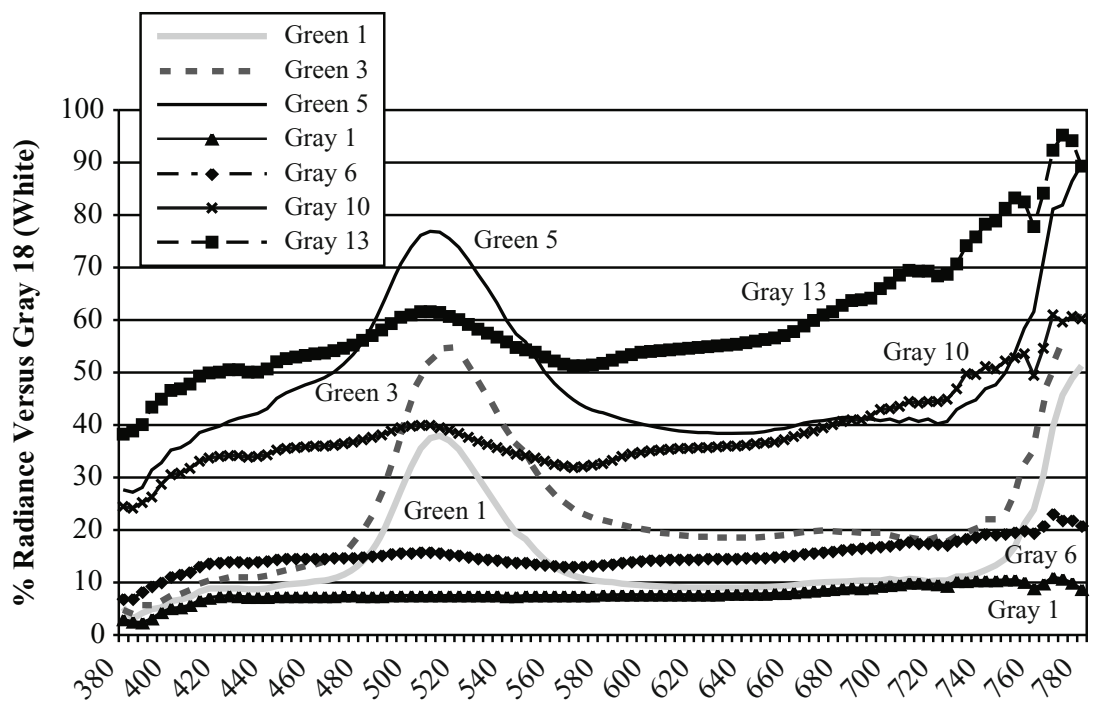

Wavelength

Figure 2. Transmission spectra for selected green and gray stimuli versus the white stimulus used in the study. 


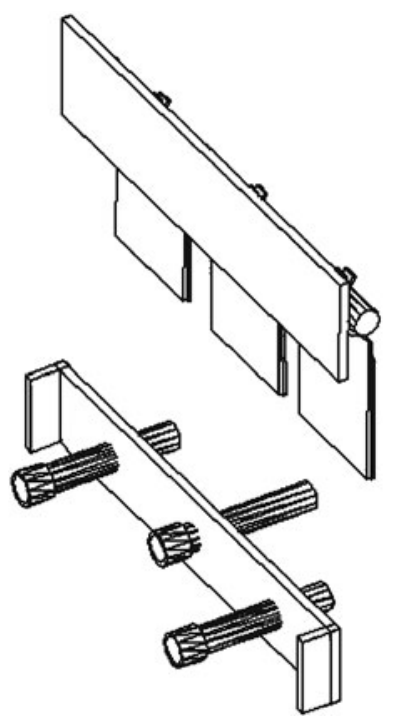

Figure 3. The apparatus consisted of two pieces. The upper piece allowed individual stimuli to be presented with spacing between them. The lower piece contained three PVC pipes, each of which could be extended into the panda's side or pushed/pulled onto the experimenter's side, either individually or simultaneously. The two pieces were arranged to allow the stimuli to be presented directly above the three pipes.

ment only when it pushed the pipe to which the trainer pointed. After the "push" behavior was established, the subjects were presented with the first positive stimulus alone.

The white stimulus was hung from one of the three clips chosen at random. If the subject pushed the pipe under the white stimulus, it was immediately reinforced with a previously established auditory conditioned reinforcer (i.e., clicker sound) followed by primary food reinforcement consisting of a piece of leaf-eater biscuit, fruit, or vegetable (i.e., banana, apple, pear, or sweet potato). Food reinforcement was delivered by hand through the mesh onto the floor of the testing enclosure directly below the subject's head. After a subject responded correctly to the white stimulus alone at $100 \%$ for three consecutive sessions of 20 trials each, the white stimulus was paired with a different comparison gray stimulus chosen randomly from the 16 shades of gray until the subject reached a criterion of $80 \%$ correct for three consecutive sessions of 20 trials each.

\section{Testing Procedure}

Testing was a noncorrection simultaneous discrimination, wherein the subject was required to select the correct stimulus on the first response to receive reinforcement (see, e.g., Allison, 1972; Towart $\&$ Smith, 1966). This procedure was used rather than the correction procedure of Bacon and Burghardt (1976), because noncorrection discrimination often allows for faster acquisition (Allison, 1972; Towart \& Smith, 1966). At the beginning of each trial, the subject was required to touch its nose to a wooden rectangle $(20 \times 12.5 \mathrm{~cm})$ designated as a remote target when the verbal command "remote" was given. This remote target was hung on the experimenter's side of the enclosure mesh at a distance of approximately $91 \mathrm{~cm}$ from the test apparatus for the male subject and $122 \mathrm{~cm}$ for the female. Both the positive and the negative stimuli were pseudorandomly selected for each trial, with adjustments to ensure that no stimulus was repeated for more than three trials in a row. While the subject was holding its nose to the remote target, the stimuli for that trial were hung from the clips above the pipes. That is, the positive stimulus was hung from one clip, and two gray comparison stimuli were hung from the other clips. Stimulus placement was pseudorandomly determined, with adjustment to prevent the positive stimulus from being on the same pipe more that three times in a row (see Table 1). Then the command "push" was given, indicating that the subject should walk to the test apparatus and respond by pushing one pipe toward the experimenter's side of the apparatus. The experimenter scored the response as "correct" if the pipe under the positive stimulus was pushed and "incorrect" if a pipe under a comparison stimulus was pushed. Only the subject's first response was scored. As during the training phase, a correct response was immediately reinforced with the conditioned reinforcer followed by primary food reinforcement. An incorrect response was immediately followed by approximately $5 \mathrm{sec}$ of a 4$\mathrm{kHz}$ buzzing sound presented via a battery-powered speaker, and the subject was required to return to the remote target and remain there for an intertrial interval of approximately $30 \mathrm{sec}$ before the next trial could begin. The next trial began with the subject's nose on the remote target after the command "remote" was given and the stimuli had been arranged.

The total amount of reinforcement available in each session was $150 \mathrm{~g}$ (i.e., $50 \mathrm{~g}$ of biscuits and $100 \mathrm{~g}$ of fruit). This amount of food was routinely fed to the subjects each morning prior to the start of this study. Within $30 \mathrm{~min}$ of the end of a session, the subjects received any remaining food, regardless of their performance.

One session of 20 trials per day was conducted with each subject five to six times per week. For all tasks except Task 2 (described below), the subjects were tested on the positive stimulus with two gray comparison stimuli until they achieved 16 correct responses out of 20 trials ( $80 \%$ correct) for three consecutive sessions before testing started on the next task.

The tasks were arranged as follows.

Task 1 . White was the positive stimulus paired with two gray comparison stimuli for each trial.

Task 2. This task was a reversal; the positive stimulus was switched from white to black. If the reversal of the positive stimulus led to a drop in performance, this provided evidence that the subjects did not learn the initial discrimination on the basis of unintended cues. Initially, this task used black with two gray comparison stimuli. However, both subjects performed below chance after nearly 200 trials. Therefore, the task was simplified to black paired with only one gray stimulus. Because of this, the probability of performance based on chance alone for this task was $50 \%$.

Table 1

Sample Trials in Which $\mathbf{S}+$ Is Green

\begin{tabular}{clll}
\hline & \multicolumn{3}{c}{ Pipe Number } \\
\cline { 2 - 4 } Trial Number & \multicolumn{1}{c}{ 1 } & \multicolumn{1}{c}{2} \\
\hline 1 & gray 16 & green 3 & gray 17 \\
2 & gray 12 & gray 5 & green 2 \\
3 & green 1 & gray 3 & gray 15 \\
4 & gray 9 & green 4 & gray 13 \\
5 & green 5 & gray 8 & gray 16 \\
6 & gray 4 & gray 6 & green 4 \\
7 & green 3 & gray 10 & gray 9 \\
8 & gray 7 & green 2 & gray 17 \\
9 & gray 5 & gray 18 & green 3 \\
10 & gray 14 & green 1 & gray 2 \\
11 & gray 9 & gray 3 & green 5 \\
12 & green 4 & gray 6 & gray 10 \\
13 & gray 15 & green 3 & gray 5 \\
14 & gray 7 & gray 14 & green 2 \\
15 & gray 3 & green 4 & gray 1 \\
16 & green 5 & gray 3 & gray 4 \\
17 & gray 5 & gray 12 & green 5 \\
18 & gray 9 & green 1 & gray 15 \\
19 & gray 16 & gray 4 & green 5 \\
20 & gray 1 & green 3 & gray 10 \\
\hline
\end{tabular}

Note-This session was conducted with the female on October 17, 2003 . 
Task 3. For this task, the positive stimulus was green. Both subjects were initially tested on a green versus two grays. However, because both subjects selected the same pipe for approximately $90 \%$ of the trials over four consecutive sessions, the task was simplified to green without any comparison stimuli. The subjects were then required to reach either $80 \%$ correct for three consecutive sessions or $100 \%$ correct for one session. After the subjects passed green alone, both were tested on green versus one gray. After a subject reached $80 \%$ correct for one session, green versus two grays was tested. During this task, the male stopped eating biscuits and fruit. Testing with the male was interrupted for 45 days, until he started eating the food used as primary reinforcement again.

Task 4. After the female reached criterion on green versus two grays, she was tested with blue as the positive stimulus. She achieved $100 \%$ correct responses on blue presented alone on her first day of testing. She was then tested on blue versus one gray until she reached the criterion of $80 \%$ for three consecutive sessions. She was then tested on blue versus two grays. During the blue phase of testing, the female received treatment for a scratched cornea unrelated to this study, but this did not interrupt testing although it may have affected performance. The male was not tested on Task 4 because of the extended period required for him to reach criterion for Task 3 .

Task 5. Red was the positive stimulus for this task. The female reached criterion (i.e., $100 \%$ correct) for red presented alone in the first session. She achieved criterion (i.e., $80 \%$ correct for three consecutive sessions) for red versus one gray within five sessions. She was then tested on red versus two grays. Testing was suspended for 20 days during her estrous cycle, because her appetite was significantly reduced. Testing resumed when her appetite returned to normal. The male achieved $100 \%$ correct responses on red alone within two sessions and achieved criterion for red versus one gray within three sessions. He was then tested on red versus two grays.

\section{Data Analysis}

The data were examined graphically in order to analyze the patterns of response. The data were also compared with chance, which was modeled through a binomial distribution. Given a criterion of $80 \%$, the probability of the subjects' responding correctly on 16 or more trials out of 20 consecutive trials was $2.51 \times 10^{-5}$ if there were three stimuli (chance $=33 \%$ ). It was $5.91 \times 10^{-3}$ if there were two stimuli (chance $=50 \%$ ). Extending the probability to three sessions in a row at $80 \%$ correct, the probability of the subject's achieving criterion was $1.58 \times 10^{-14}$ for three stimuli and $2.06 \times 10^{-7}$ for two stimuli. Therefore, criterion performance for all phases was statistically significant above chance performance (all $p$ values were well below .01).

\section{RESULTS}

\section{Task 1}

For white versus two grays, the male reached criterion ( $80 \%$ for 3 consecutive sessions) in 317 trials (23 sessions; see Figure 4 and Table 2) and the female reached criterion in 250 trials ( 17 sessions). Visual examination of the data reveals that the male performed above chance for all trials, whereas the female had 2 early sessions that were actually below chance.

\section{Task 2}

For black paired with one gray, the male reached criterion in 824 trials (47 sessions) and the female reached criterion in 822 trials (46 sessions; see Figure 5). Both subjects had highly variable performance, including many sessions with below chance performance.

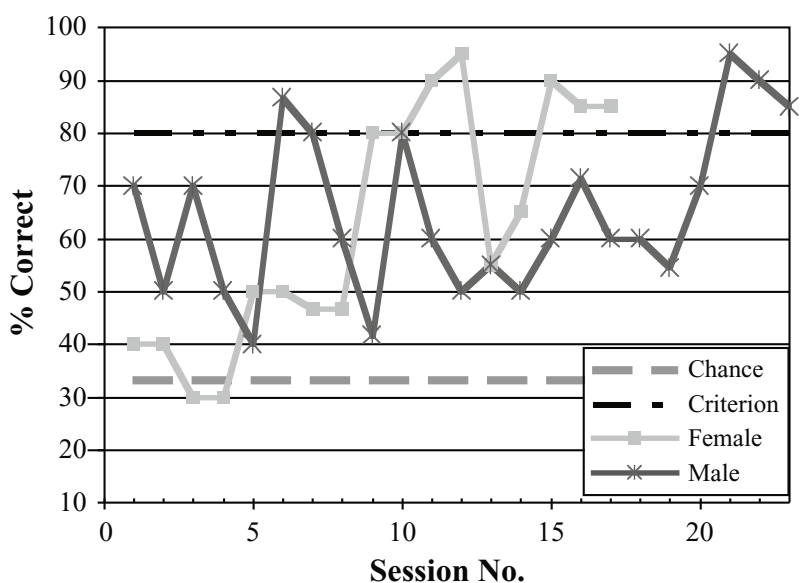

Figure 4. Percentage of correct trials for subjects on Task 1 (white vs. two grays).

\section{Task 3}

For green versus two grays, the female reached criterion in 860 trials ( 53 sessions; see Figure 6). The male reached criterion in 759 trials (44 sessions). Again, performance was variable, but it was mostly above chance.

\section{Task 4}

Only the female was tested with blue as a positive stimulus. She reached criterion on blue versus two grays in 405 trials (21 sessions; see Figure 7). Performance for this task was less variable, with only 1 session below chance.

\section{Task 5}

For red versus two grays, the female reached criterion in 560 trials ( 28 sessions; see Figure 8). The male reached criterion in 120 trials (6 sessions). Neither subject had below chance performance in this task.

\section{DISCUSSION}

Giant pandas were able to discriminate shades of green, red, and blue stimuli from numerous shades of gray. Because brightness was eliminated as a cue, these discriminations can be attributed to color vision, thus providing experimental evidence that the giant panda's visual capabilities, including color vision, are comparable to those of other bears (Bacon \& Burghardt, 1976) and other car-

Table 2

Number of Testing Trials Required for Each Subject to Reach Criterion in Each Task

\begin{tabular}{ccc}
\multicolumn{2}{c}{ to Reach Criterion in Each Task } \\
\cline { 2 - 3 } Task & Male & Female \\
\hline 1. White vs. 2 grays & 317 & 250 \\
2. Black vs. 1 gray & 824 & 822 \\
3. Green vs. 2 grays & 759 & 860 \\
4. Blue vs. 2 grays & n.a. & 405 \\
5. Red vs. 2 grays & 120 & 560 \\
\hline
\end{tabular}




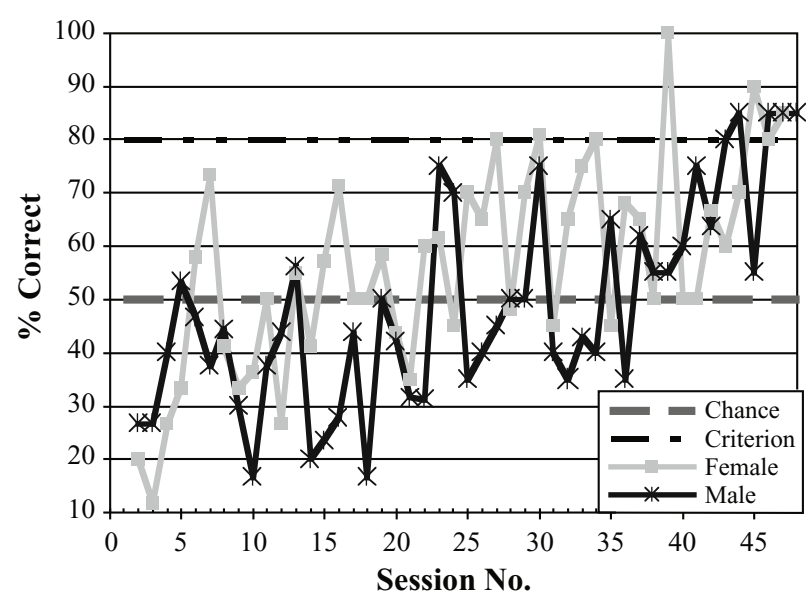

Figure 5. Percentage of correct trials for subjects on Task 2 (black vs. one gray).

nivores that are not strictly nocturnal (see, e.g., Ducker, 1964; Jacobs, 1993). The findings of this study are consistent with the known activity levels of giant pandas during daylight hours (Schaller et al., 1985), but inconsistent with the hypothesis that giant panda vision is not well developed and similar to that of nocturnal mammals (Schaller, 1993). These findings are also consistent with the physiology of the giant panda's eye, which contains both rods and cones (Hu, 2001).

On the basis of their behavior, ecology, and performance in this study, giant pandas are most likely dichromats, as are most other carnivores that have been studied. Dichromacy appears to be the most widespread form of mammalian color vision, with the main exceptions being a small number of nocturnal monochromats and the trichromatic primates (Jacobs, 1993). However, the discovery of a neutral point (i.e., a wavelength at which the ratio of the responses of the two overlapping cones is equivalent to gray, which is an identifying trait of dichromatic vi- sion) in the giant panda would confirm this claim. Further behavioral tests should be performed to identify a neutral point (Jacobs, 1993).

There were many difficulties in reaching criterion performance throughout the study. For example, changing the positive stimulus from one task to another led to extended below chance performance and occasional displays of apparent frustration (e.g., pacing and bleating vocalizations). The subjects also frequently tried to correct their responses from one trial to the next. For example, a subject would respond incorrectly on a trial, and then on the next trial select the pipe that was correct on the previous trial. This behavior persisted even when the intertrial interval was increased and/or when, in an effort to distract the subject, it was given commands for other previously trained behaviors between trials. This correction perseveration behavior suggests that a future study of giant panda memory may be warranted, because both subjects seemed capable of remembering the correct choice from the previous trial. The subjects also developed response biases in which they would choose the same pipe for many consecutive trials. In an effort to disrupt this behavior, the positive stimulus was not presented on the preferred pipe until the nonpreferred pipe was selected. However, the male then began switching his preference to another pipe. This pattern continued over several cycles and forced the presentation of the positive stimulus on the preferred pipe occasionally to prevent him from switching his response bias to another pipe. The female's response bias sometimes resulted in her placing her paw on the correct pipe and then removing it to push her current preferred pipe. Despite these difficulties, the giant pandas were able to demonstrate appropriate discriminations if given enough trials.

Although it is difficult to compare our findings with those of other visual discrimination studies because the methodologies differ, the giant pandas required more trials to reach criterion than were expected on the basis of findings with other species. Goldfish (Carassius auratus) reached $90 \%$ correct criterion for a color discrimination

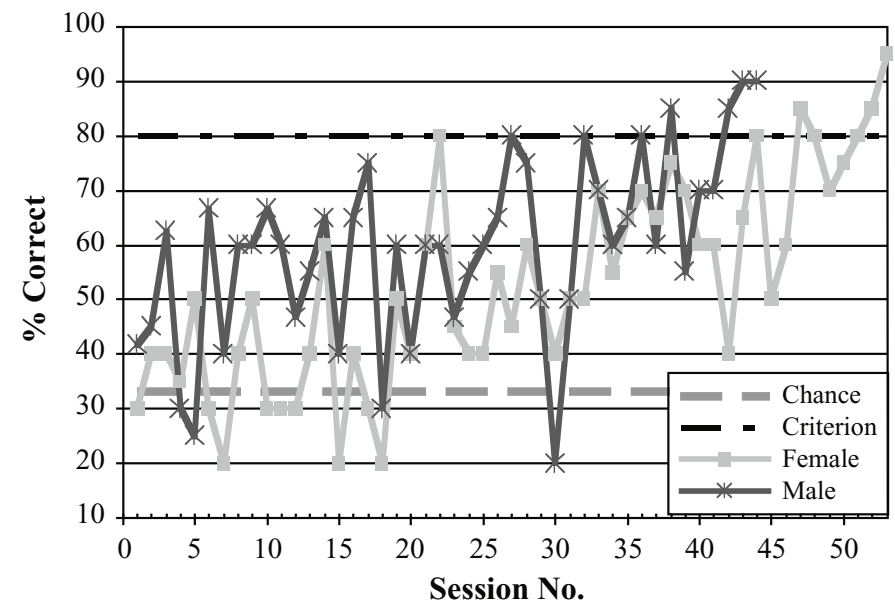

Figure 6. Percentage of correct trials for subjects on Task 3 (green vs. two grays). 


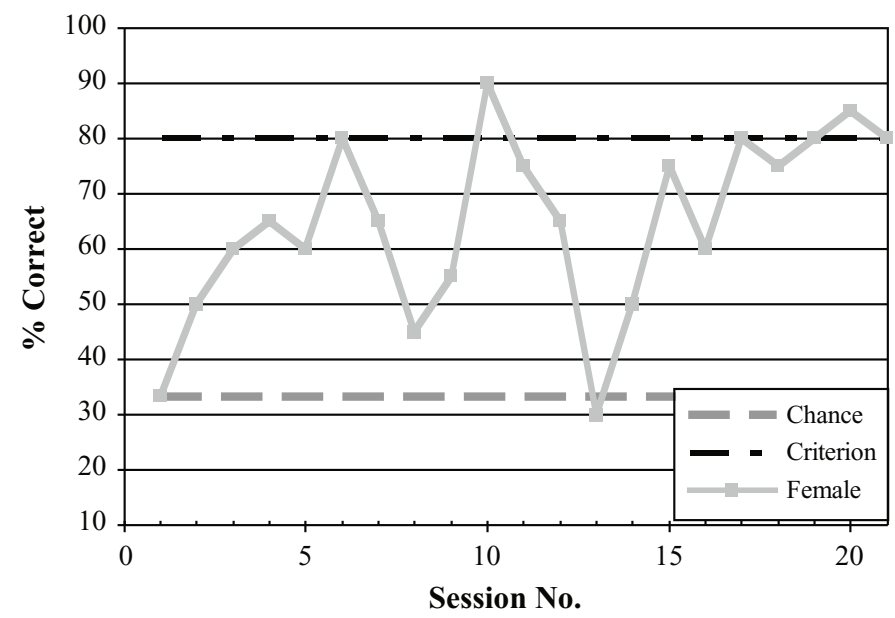

Figure 7. Percentage of correct trials for the female on Task 4 (blue vs. two grays).

task in less than 100 trials (Muntz \& Cronley-Dillon, 1966). Two wild boars (Sus scrofa leucomystax) were trained to discriminate blue from gray to a criterion of $70 \%$ correct for three sessions in a row in 120 and 60 trials; however, they could not learn other discriminations (Eguchi, Tanida, Tanaka, \& Yoshimoto, 1997). Pick, Lovell, Brown, and Dail (1994) trained a domestic horse (Equus caballus) to a discrimination criterion of 10 successive correct responses in 102 trials for red versus gray and 243 trials for blue versus gray. The black bears in Bacon and Burghardt's (1976) study required very different lengths of time to demonstrate discrimination, because 1 subject was used to develop the procedure and the 2 nd subject was then tested with that procedure. The 1 st bear required approximately 550 trials (i.e., 31 sessions of 16-19 trials) to reach the criterion of 9 of 10 consecutive trials correct. The 2 nd bear required only about 210 trials (i.e., 12 sessions of 16-19 trials) to reach criterion.
On the basis of these findings, giant pandas were expected to reach criterion in approximately 500 trials. Both subjects learned the discrimination with white as the positive stimulus in well under 500 trials. However, performance was much slower on the black and green tasks, in which both subjects required over 750 trials to reach criterion.

Jacobs (1981) stated that extensive training was required in order to demonstrate color vision in the cat and suggested that the cat's color vision is not highly developed, or at least that color is not an important source of environmental information for the cat. Given that it took more trials for giant pandas to demonstrate color discrimination than it took black bears, color may not be as important for giant pandas as other stimuli are (e.g., spatial stimuli) (Jacobs, 1981) under natural conditions. In a study investigating cues that bears use to perform a foraging task, giant pandas reached criterion performance (i.e., three or

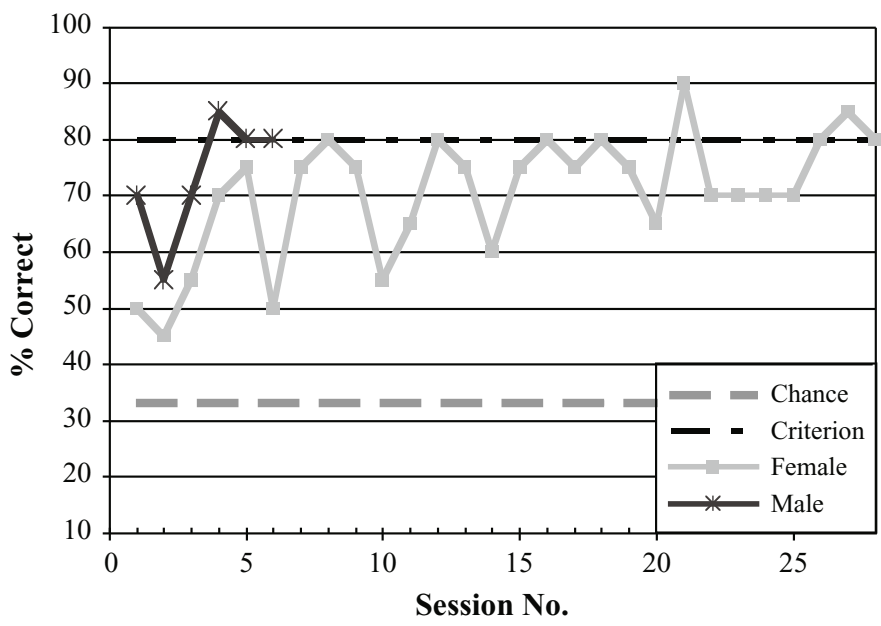

Figure 8. Percentage of correct trials for subjects on Task 5 (red vs. two grays). 
more correct choices of the first four choices in five consecutive trials) on a task involving spatial cues but not on one involving black and white visual cues (Tarou, 2003). Conversely, in the same study, spectacled bears reached criterion performance for the visual task (Tarou, 2003). It has been hypothesized that color vision aids foraging by enhancing the distinction of an object from its background (Jacobs, 1981). Giant pandas have color vision, but color may not be as salient a cue for bamboo selection as it is for other bears that forage for fruits and a wide range of vegetation types. It would be interesting to use the methodology from this study to test other bear species, particularly spectacled bears, which are most closely related to giant pandas (Waits, Sullivan, O’Brien, \& Ward, 1999) and are highly frugivorous (Weinhardt, 1993), to determine whether they could learn hue discriminations in fewer trials.

On the other hand, color may indeed contribute to more effective foraging on bamboo. Color variation may guide leaf choice or indicate nutrient content and may be especially important for giant pandas when they select bamboo patches from a distance. For example, color discrimination may help giant pandas avoid dying bamboo on the basis of visual changes accompanying periodic bamboo flowering and death, which can occur in small regions or on entire mountainsides (Schaller et al., 1985). Therefore, future studies could investigate the ecologically relevant uses of color to determine whether giant pandas prefer particular colors of bamboo leaves and culms and how that relates to nutrient content.

\section{REFERENCES}

Allison, J. P. (1972). Training procedure and task difficulty in brightness and position discriminations by rats. Psychological Reports, 31, 71-76.

BACON, E. S. (1973). Investigation on perception and behavior of the American black bear (Ursus americanus). Unpublished doctoral dissertation, University of Tennessee, Knoxville.

BACON, E. S., \& BurghardT, G. M. (1976). Learning and color discrimination in the American black bear. In M. R. Pelton, J. W. Lenfer, \& G. E. Folks, Jr. (Eds.), Bears-Their biology and management (pp. 27-36). Morges, Switzerland: International Union for the Conservation of Nature \& Natural Resources.

Birgersson, J., Alm, U., \& Forkman, B. (2001). Colour vision in fallow deer: A behavioural study. Animal Behaviour, 61, 367-371.

Chausseil, M. (1992). Evidence for color vision in procyonides: Comparison between diurnal coatis (Nasua) and nocturnal kinkajous (Potos flavus). Animal Learning \& Behavior, 20, 259-265.

Daw, N. W., \& Pearlman, A. L. (1970). Cat colour vision: Evidence for more than one cone process. Journal of Physiology, 211, 125-137.

DeVoss, J. C., \& Ganson, R. (1915). Color blindness of cats. Journal of Animal Behaviour, 5, 115-139.

DUCKER, G. (1964). Colour-vision in mammals. Journal of the Bombay Natural History Society, 61, 572-586.

Eguchi, Y., Tanida, H., Tanaka, T., \& Yoshimoto, T. (1997). Color discrimination in wild boars. Journal of Ethology, 15, 1-7.

GregG, F. M., Jamison, E., Wilkie, R., \& Radinsky, T. (1929). Are dogs, cats, and raccoons color blind? Journal of Comparative Psychology, 9, 379-395.

Hu, H. (2001). [Research on the giant panda]. Shanghai: Shanghai Scientific and Technological Education Publishing House. (Published in Chinese)
JACOBS, G. H. (1981). Comparative color vision. New York: Academic Press.

JACOBS, G. H. (1993). The distribution and nature of colour vision among the mammals. Biological Review, 68, 413-471.

JaCoBS, G. H., \& DeEgan, J. F., II (1992). Cone photopigments in nocturnal and diurnal procynoids. Journal of Comparative Physiology A, 17, 351-358.

Jacobs, G. H., Deegan, J. F., II, Crognale, M. A., \& Fenwick, J. A. (1993). Photopigments of dogs and foxes and their implications for canid vision. Visual Neuroscience, 10, 173-180.

LaIDler, K., \& LaIDler, L. (1992). Pandas: Giants of the bamboo forest. London: BBC Books.

Loop, M. S., Bruce, L. L., \& Petuchowski, S. (1979). Cat color vision: The effect of stimulus size, shape and viewing distance. Vision Research, 19, 507-513.

McNAmeE, T. (1984). The grizzly bear. New York: Knopf.

Muntz, W. R. A., \& Cronley-Dillon, J. R. (1966). Colour discrimination in goldfish. Animal Behaviour, 14, 351-355.

Neitz, J., Geist, T., \& Jacobs, G. H. (1989). Color vision in the dog. Visual Neuroscience, 3, 119-125.

Pelton, M. R. (2000). The American black bear. In I. Stirling (Ed.), Bears (pp. 108-117). San Francisco: Fog City Press.

Pick, D. F., Lovell, G., Brown, S., \& DAIL, D. (1994). Equine color perception revisited. Applied Animal Behaviour Science, 42, 61-65.

Ringo, J., Wolbarsht, M. L., WaGner, H. G., Crocker, R., \& AMthor, F. (1977). Trichromatic vision in the cat. Science, 198, 753-755.

Schaller, G. (1993). The last panda. Chicago: University of Chicago Press.

Schaller, G., Hu, J., Pan, W., \& Zhu, J. (1985). The giant pandas of Wolong. Chicago: University of Chicago Press.

ShePARD, P., \& SANDERS, B. (1985). The sacred paw: The bear in nature, myth, and literature. New York: Viking.

Swaisgood, R. R., Lindburg, D. G., \& Zhang, H. (2002). Discrimination of oestrous status in giant pandas (Ailuropeda melanoleuca) via chemical cues in urine. Journal of Zoology, 257, 381-386.

Swaisgood, R. R., LindburG, D. G., \& ZHOU, X. (1999). Giant pandas discriminate individual differences in conspecific scent. Animal Behaviour, 57, 1045-1053.

TANSLEY, K. (1965). Vision in vertebrates. London: Cox \& Wyman.

TAROU, L. R. (2003). An examination of the role of associative learning and spatial memory in foraging in two species of bear (Family: Ursidae) (Doctoral dissertation, Georgia Institute of Technology, 2003). Dissertation Abstracts International, 64B, 5260.

Towart, E. M., \& SMITH, W. A. S. (1966). Comparison of training methods, type of problem, and apparatus in acquisition and extinction. Psychological Reports, 19, 47-52.

TRITSCH, M. F. (1993). Color choice behavior in cats and the effect of changes in the color of the illuminant. Naturwissenschaften, 80, 287288.

Van Valkenburgh, B. (2000). The biology of bears. In I. Stirling (Ed.), Bears (pp. 50-61). San Francisco: Fog City Press.

Waits, L. P., Sullivan, J., O’Brien, S. J., \& Ward, R. H. (1999). Rapid radiation events in the family Ursidae indicated by likelihood phylogenetic estimation from multiple gene fragments of mtDNA. Molecular Phylogenetics \& Evolution, 13, 82-92.

WALLS, G. L. (1942). The vertebrate eye and its adaptive radiations. Bloomfield Hills, MI: Cranbrook Institute of Science.

WeinhardT, D. (1993). The spectacled bear. In I. Stirling (Ed.), Bears (pp. 134-139). San Francisco: Fog City Press.

XIE, Z., \& GIPPS, J. (2003). The 2003 international studbook for giant panda (Ailuropoda melanoleuca). Beijing: China Association of Zoological Gardens.

Zeveloff, S. I. (2002). Raccoons: A natural history. Washington, DC: Smithsonian Institution Press.

(Manuscript received March 8, 2005; revision accepted for publication November 22, 2005.) 